\title{
A parceria universidade-escola: utopia ou possibilidade de formação continuada no âmbito das políticas públicas?*
}

\author{
ADAIR MENDES NACARATO \\ Universidade São Francisco, Itatiba, SP, Brasil
}

\section{RESUMO}

Este artigo tem como objetivo apresentar contextos de formação docente e de políticas públicas, com destaque para alguns constructos teóricos elaborados nas últimas décadas pelo campo da pesquisa educacional e o modo como eles têm sido apropriados e ressignificados pelas políticas públicas. Apresenta, ainda, recentes programas instituídos pela nova Coordenação de Aperfeiçoamento de Pessoal de Nível Superior (nova CAPES) e relata uma pesquisa realizada em um deles, o Observatório da Educação. Os resultados desta pesquisa evidenciam a possibilidade de adesão a um desses programas e a promoção de uma parceria universidade-escola que estimule a reflexão e a criticidade dos professores quanto às políticas públicas e aos documentos prescritivos que chegam às escolas.

PALAVRAS-CHAVE

formação docente; políticas públicas; parceria universidade-escola.

* Trata-se de texto recomendado pelo Comitê Científico da $36^{a}$ Reunião Anual da Associação Nacional de Pós-Graduação e Pesquisa em Educação (ANPEd). O título do artigo foi alterado e o texto ampliado. $\mathrm{O}$ título anterior, quando veio a carta-convite da Revista Brasileira de Educação, era: "Políticas públicas de formação do professor na educação básica: pesquisas, programas de formação e práticas”. 


\title{
THE UNIVERSITY-SCHOOL PARTNERSHIP: UTOPIA OR A POSSIBILITY OF EXTENDED TRAINING IN THE PUBLIC POLICY DOMAIN?
}

\begin{abstract}
The goal of this text is to present some contexts that deal with the training of university professors and public policy, with an emphasis on theoretical constructs elaborated in the last few decades in the field of educational research and how these constructs have been appropriated and re-signified by public policies. This paper also presents some recent programs implemented by Coordenação de Aperfeiçoamento de Pessoal de Nível Superior (nova CAPES), as well as research done on one of these programs, the Observatório da Educação. The results of this research show the possibility of adherence to one of these programs and the promotion of a university-school partnership that stimulates reflection and critical appraisal on the part of professors with respect to public policies and the prescriptive documents that reach schools.

KEYWORDS

university professor training; public policy; university-school partnership.
\end{abstract}

\section{LA COLABORACIÓN UNIVERSIDAD-ESCUELA: ¿UTOPÍA O POSIBILIDAD DE FORMACIÓN CONTINUADA EN EL ÁMBITO DE LAS POLÍTICAS PÚBLICAS?}

\section{RESUMEN}

Este artículo tiene como objetivo presentar contextos de formación docente y de políticas públicas, con destaque para algunos constructos teóricos elaborados en las últimas décadas por el campo de investigación educativa y la forma como vienen siendo apropiados y resignificados por las políticas públicas. Presenta también programas recientes instituidos por la Coordenação de Aperfeiçoamento de Pessoal de Nível Superior (nueva CAPES) y relata una investigación realizada en uno de ellos, el Observatório da Educação. Los resultados de esa investigación ponen de manifestó la posibilidad de adhesión a uno de esos programas y de la promoción de una colaboración universidad-escuela que estimule la reflexión y la criticidad de los profesores en cuanto a las políticas públicas y a los documentos prescriptivos que llegan a las escuelas.

PALABRAS CLAVES

formación docente; políticas públicas; colaboración universidad-escuela. 
Inicio as reflexões do presente texto com algumas ideias de Nóvoa (2009, p. 12, grifos do original) sobre a formação de professores:

Assistimos, nos últimos anos, a um regresso dos professores à ribalta educativa, depois de quase quarenta anos de relativa invisibilidade. A sua importância nunca esteve em causa, mas os olhares viraram-se para outros problemas: nos anos 70, foi o tempo da racionalização do ensino, da pedagogia por objetivos, do esforço para prever, planificar, controlar; depois, nos anos 80 , vieram as grandes reformas educativas, centradas na estrutura dos sistemas escolares e, muito particularmente, na engenharia do currículo; nos anos 90, dedicou-se uma atenção especial às organizações escolares, ao seu funcionamento, administração e gestão. [...] Os professores reaparecem, neste início do século XXI, como elementos insubstituíveis não só na promoção das aprendizagens, mas também na construção de processos de inclusão que respondam aos desafios da diversidade e no desenvolvimento de métodos apropriados de utilização das novas tecnologias.

E como analisar esse retorno dos professores ao centro das preocupações de pesquisadores e de elaboradores de reformas públicas em educação? Qual é, de fato, a centralidade dos professores nesse debate? Se, por um lado, a formação docente é central nas pautas dessas políticas, por outro, do ponto de vista da pesquisa, esse é o campo de investigação que reúne o maior número de trabalhos, haja vista o número de artigos submetidos aos grupos de trabalhos de formação docente a cada evento: tanto o GT08, da ANPEd, quanto o GT07, da Sociedade Brasileira de Educação Matemática (SBEM), são grupos que recebem um número expressivo de trabalhos, e, no próprio GT19, Educação Matemática, da ANPEd, o maior número de trabalhos recebidos anualmente se centra nessa temática.

Pode-se indagar por que essas pesquisas não provocam impactos nas políticas públicas. Em meu entender, há um conflito nas lógicas que orientam esses dois movimentos - as pesquisas e as políticas públicas -, embora na última década tenham surgido programas mais abrangentes de formação docente, com a criação da nova Coordenação de Aperfeiçoamento de Pessoal de Nível Superior (CAPES). $\mathrm{Se}$, por um lado, os documentos que emanam dos poderes centrais visam abranger o maior número possível de professores, por outro, importa saber se os professores têm recebido apoio para participar desses projetos de formação e se tais projetos atendem aos anseios e às necessidades dos professores. Quando me refiro a apoio, estou referindo-me, principalmente, a duas condições: inclusão da formação na jornada de trabalho e possibilidades de trabalho coletivo no interior das escolas. Não se acredita mais em projetos de formação propostos pelos sistemas de ensino, nos quais os professores são convocados a participar fora do seu horário de trabalho, principalmente aos sábados, sem que isso faça parte de sua jornada docente. E tampouco se acredita naqueles em que o coletivo das escolas não esteja envolvido.

Assim, no presente texto, apresento algumas reflexões sobre contextos de formação docente e contextos de políticas públicas ou de programas de formação elaborados pelo Ministério da Educação (MEC), visando enriquecer o debate sobre a formação do professor da escola básica. Apresento algumas reflexões que, 
ao mesmo tempo, apontam possibilidades para a formação docente do professor da escola básica decorrentes de investigações e a forma como as reformas educacionais têm sido gestadas e colocadas em prática, apoiando-se em construtos teóricos criados no âmbito das pesquisas, mas ressignificados nos documentos prescritivos das políticas, que visam atender princípios neoliberais e empresariais, pautados em índices de desempenho de alunos e professores. Apresento, de forma sintetizada, os programas atuais colocados em prática pela nova CAPES, que podem ser indicativos de atendimento de alguns anseios da comunidade escolar. Finalizando, exponho resultados de uma pesquisa que analisou uma experiência de formação apoiada em um desses programas, mas se constituiu em prática de resistência, em uma parceria universidade-escola, em um projeto de formação continuada.

\section{A FORMAÇÃO DOCENTE NO ÂMBITO DA PESQUISA E DAS POLÍTICAS PÚBLICAS: ALGUNS CONTEXTOS}

No campo da pesquisa, cada vez mais, os pesquisadores têm-se voltado para as práticas de formação docente que colocam o professor como protagonista do processo. Alguns construtos teóricos emergiram das pesquisas na década de 1990 - em especial o de professor reflexivo e o de professor pesquisador. Diferentes trabalhos discutiram e apresentaram contextos favoráveis à reflexão como prática social coletiva e à pesquisa do professor como possibilidade de emancipação social. Conforme afirma Pimenta (2002, p. 18), tais conceitos estavam no cerne do "movimento de valorização da formação e da profissionalização de professores surgido em diferentes países a partir dos anos 1990"e orientaram discursos de pesquisadores e políticos brasileiros.

Os estudos sobre o professor reflexivo surgiram no momento em que se buscava romper com o modelo de racionalidade técnica, de princípios positivistas, que marcou a formação docente no Brasil, e aproximar-se de outros paradigmas que se pautavam no pensamento do professor. Segundo Pereira (2002, p. 26), nesse contexto de valorização do docente como um prático reflexivo, "os professores têm sido vistos como um profissional que reflete, questiona e constantemente examina sua prática pedagógica cotidiana, a qual por sua vez não está limitada ao chão da escola”.

Outro movimento paralelo ao do professor reflexivo foi o de professor pesquisador. A origem do conceito de professor pesquisador tem a ver com a postura política de reconhecer o professor como produtor de saberes, rompendo, tal como revela Zeichner (1998), com a divisão entre pesquisas dos professores e pesquisas acadêmicas. Os professores da escola básica são capazes de refletir sobre suas práticas, formular questões sobre os cotidianos de suas salas de aula e buscar respostas a essas questões, sistematizando experiências e produzindo saberes. No entanto, não se trata apenas de dar esse status de pesquisador aos professores da escola básica: é importante reconhecê-los também como pesquisadores, inserindo-os em eventos científicos nos quais possam realizar palestras, participar de mesas-redondas e socializar seus trabalhos.

Encontrávamo-nos, no início dos anos 2000, em um cenário bastante fértil de ideias que redirecionavam as concepções de formação docente. No entanto, a 
fertilidade desses conceitos ficou restrita ao campo da pesquisa ou a sua apropriação e ressignificação pelas políticas públicas acabou por merecer críticas. Entre estas, destacam-se as de Pimenta (2002). Para a autora, as ideias de Donald Schön sobre professor reflexivo foram apropriadas e ampliadas em diferentes países, principalmente nos contextos de reformas curriculares e, em especial, nos currículos de formação docente. Como propiciar uma formação adequada para formar professores reflexivos e pesquisadores? Como possibilitar que a escola se torne um espaço de reflexão dos professores? Sem dúvida, são questões que nos instigam.

Vale destacar que os conceitos de professor reflexivo e professor pesquisador foram incorporados nas políticas de formação inicial do professor da escola básica, em especial nas Diretrizes Curriculares para Formação de Professores, publicadas em 2002 na resolução n. 1, de 18 de fevereiro de 2002 (Brasil, 2002), que emprega expressões como "ação-reflexão-ação" e "práticas investigativas".

No entanto, passados dez anos dessas orientações para a formação do professor da escola básica, os estudos têm apontado que poucas mudanças ocorreram nos cursos de licenciatura. Gatti e Barreto (2009, p. 82), por exemplo, ao analisarem as licenciaturas presenciais no Brasil, concluem:

Ainda que em diferentes momentos históricos os professores tenham desempenhado importante papel na reconfiguração do currículo da educação básica, a multiplicação de disciplinas e o engessamento do currículo em grades curriculares de feição enciclopédica, sem uma discussão mais aprofundada do seu escopo na educação básica, pode estar servindo mais a interesses ligados à ampliação de postos de trabalho do que propriamente às necessidades de formação dos estudantes.

A discussão desses conceitos trouxe à tona as questões organizacionais da escola e do trabalho docente, tais como: os projetos pedagógicos que valorizam o trabalho coletivo e a formação na própria escola; as condições de trabalho dos professores, salários e carreira; os processos de constituição identitária docente; as complexas demandas que chegam às escolas; os impactos das tecnologias de informação e comunicação.

Em busca de análise dos contextos organizacionais de formação docente, a escola tem sido apontada como lócus privilegiado de formação, e o trabalho coletivo surge como instância de reflexão e pesquisa do professor. Entre os defensores da escola como local de formação e de aprendizagem, destaco Canário (2000) e Hargreaves (2004). Canário (2000) defende que a aprendizagem profissional - ou, como diz o autor, "formação sentada na escola" $-{ }^{1}$ ocorre nas instituições em que

1 Rui Canário utiliza a expressão "sentada" como forma de se contrapor àquela presente nos discursos: a formação "centrada na escola". Para ele, a expressão "sentada na escola" já sinaliza que a formação deve ocorrer onde as práticas estão presentes, ou seja, na escola. Ele parte do pressuposto de que é na escola que os professores aprendem; portanto, caberia à escola gerir a formação dos professores, bem como os recursos públicos destinados a essa formação. 
o trabalho se realiza. No caso específico dos professores, significa substituir uma cultura fortemente individualista por uma cultura colaborativa, com um trabalho de equipe que exerga, na totalidade organizacional da escola, o seu caráter sistêmico. Nesse contexto, o professor é visto como "um analista simbólico a quem compete equacionar e 'construir' problemas, no terreno da prática, marcada pela incerteza e a complexidade, e não a dar respostas previamente aprendidas para situações inteiramente previsíveis" (idem, p. 14, grifo do original).

Hargreaves (2004, p. 141-142), ao defender "a escola como comunidade de aprendizagem", argumenta:

As comunidades de aprendizagem profissional levam a avanços intensos e mensuráveis na aprendizagem dos alunos. Em lugar de produzir consertos rápidos a partir de mudanças superficiais, elas criam e dão apoio a melhorias sustentáveis e duradouras, porque constroem a habilidade e a capacidade profissionais para manter a escola avançando.

\section{E complementa:}

As comunidades de aprendizagem profissional promovem e pressupõem atributos fundamentais da sociedade do conhecimento, como trabalho coletivo, investigação e aprendizagem permanente. Ao contrário dos regimes de individualismo competitivo e corrosivo, que utilizam os dados para impor constrangimento a professores de baixo desempenho, as comunidades profissionais de aprendizagem os utilizam para sustentar e promover a melhoria conjunta da equipe. (idem, p. 181)

Nas propostas de ambos os autores, predomina a concepção de aprendizagens em contextos de trabalho coletivo. $\mathrm{O}$ trabalho coletivo e/ou colaborativo também se vem fazendo presente em muitas pesquisas desde o início da década de 2000. O estudo meta-analítico realizado por Passos et al. (2006) constatou que várias pesquisas no âmbito da educação matemática, realizadas em grupos colaborativos, apontaram para as potencialidades do trabalho coletivo/colaborativo com vistas às aprendizagens dos professores e ao desenvolvimento profissional.

Como garantir o trabalho coletivo nas escolas? Quais estratégias adotar nos projetos de formação continuada com grupos nas escolas para que os professores possam trabalhar juntos, problematizando e buscando soluções para os problemas que emergem de suas práticas?

No que se refere à formação continuada, Gatti e Barreto (2009, p. 201-202) afirmam:

Outra razão comumente invocada nos estudos críticos sobre formação continuada é a limitada, senão ausente, participação dos professores na definição de políticas de formação docente, como categoria profissional, e na formulação de projetos que têm a escola e o seu fazer pedagógico como centro. Nestas condições, eles não se envolvem, não se apropriam dos princípios, não se sentem estimulados a alterar sua prática, mediante a construção de alternativas de ação, ao 
mesmo tempo em que se recusam a agir como meros executores de propostas externas.

A análise de Freitas (2011, p. 79) também converge para essa perspectiva:

A educação é sempre um campo em disputa. Tem uma ligação tão grande com as questões relativas à formação de mão de obra em nossa sociedade que economistas, muitas vezes escalados pelos interesses dos empresários, predominam na hora de definir os caminhos da educação. Educadores profissionais pouco são ouvidos na elaboração das políticas públicas educacionais e a mídia, em particular, abre espaço para os homens de negócio e seus representantes e muito menos para educadores.

Para esse autor, além de não serem ouvidos e de não participarem das decisões que lhe dizem respeito, nos últimos anos, os professores têm sofrido uma série de regulações em seu trabalho, decorrentes das reformas educacionais pautadas em modelos empresariais: "para os reformadores empresariais, os objetivos da educação se resumem a uma 'matriz de referência' para elaborar um teste que meça habilidades ou competências básicas". Em contrapartida, "para os educadores profissionais, porém, formar para o trabalho é apenas parte das tarefas educacionais” (idem, ibidem, grifos do original).

Freitas (2007, p. 1.215) argumenta:

Uma das características essenciais no quadro que se desenha a partir da redefinição do papel do estado, originário das mudanças ocorridas no âmbito do capitalismo, é a necessidade de regulação, que adquire caráter central no campo da educação e da formação de professores.

Tal regulação, segundo a autora, inclui: diretrizes e referenciais para a escola básica; regulamentação das instituições formadoras; sistemas de avaliação de estudantes; e certificação de professores. Nesse estado regulador, o trabalho docente é reduzido "à prática individual, às suas dimensões técnicas, de modo a poder ser avaliado, mensurado e certificado, visando adaptar os professores, a escola e seus processos formativos às transformações necessárias no âmbito das reformas propostas" (idem, p. 1.215).

Constata-se, assim, um fosso entre aquilo que as pesquisas apontam sobre a formação docente desejada e o que, de fato, é prescrito nos documentos para os diferentes sistemas de ensino. Não há como destacar as recentes políticas públicas do estado de São Paulo e deixar de mencionar mais uma apropriação inadequada de conceitos emanados das pesquisas sobre formação docente: o conceito de grupo colaborativo.

Nacarato et al. (2008, p. 201), pautando-se em pesquisas realizadas no âmbito da educação matemática, analisam as condições para um grupo colaborativo: voluntariedade, identidade, espontaneidade e afetividade. Segundo as autoras: 
A participação no grupo é voluntária, no sentido de que cada membro deseja fazer parte de um determinado grupo, com predisposição para contribuir e aprender com seus pares, a partir de um interesse comum - o que imprime ao grupo uma identidade. [...] ao mesmo tempo em que adquire uma identidade própria constituída pelos objetivos comuns, não provoca a perda dos objetivos individuais, ou seja, mantém a singularidade e a identidade de cada um de seus membros. [...] A essas características, acrescentaríamos a afetividade, ressaltada por Ferreira (2003), como elemento fundamental para a construção de um grupo de trabalho colaborativo que vai se constituindo pelas relações de respeito, negociações, trocas e contribuições entre os participantes.

Dessa forma, não é possível pensar, a priori, na constituição de grupos colaborativos; eles constituem-se colaborativos ao longo do processo. E, concordando com as sínteses produzidas por Passos et al. (2006), defendo que esses grupos, quando instituídos nas próprias escolas, são promotores de aprendizagens e formação crítica dos professores, que passam a assumir-se como protagonistas de suas práticas e dos currículos que desenvolvem com seus alunos.

Contrapondo-se a essa perspectiva, em 2012, a Secretaria de Educação do Estado de São Paulo implantou o Projeto Educação Matemática nos Anos Iniciais (EMAI), de cuja apresentação destaco um trecho:

Tal pressuposto orienta o Projeto EMAI a colocar como meta o envolvimento de todos os professores que atuam nos cinco anos iniciais do ensino fundamental em situações de estudo e de reflexão sobre a atuação em sala de aula. Para tanto, sua ação central é a constituição de Grupos de Educação Matemática dos Anos Iniciais nas escolas, usando o horário destinado a atividades pedagógicas coletivas (HTPC), com reuniões quinzenais de 2 horas/aula de duração. O formato desses grupos é o de grupos colaborativos, organizados pelo professor coordenador de Ciclo I, com atividades conduzidas com a participação dos próprios professores. (São Paulo, s.d., p. 9, grifos meus)

Constata-se, assim, um equívoco no conceito de grupo colaborativo, o qual já vem imposto por um documento. Acrescente-se a isso o fato de que as sequências de atividades vêm elaboradas para a escola, cabendo aos professores apenas sua aplicação, análise e avaliação. Ou seja, mantém-se a perspectiva da racionalidade técnica, e o professor é ouvido apenas para validar ou não uma proposta que vem de fora da escola. Tal concepção se apresenta na contramão do entendimento que se tem de grupo colaborativo.

Utilizar os horários de Aula de Trabalho Pedagógico Coletivo (ATPC) para estudos é o que almeja a maioria dos formadores; no entanto, por que não deixar que os próprios professores elaborem suas propostas? Ou que, pelo menos, possam apresentar sugestões daquilo de que necessitam para suas práticas?

Esses são apenas alguns exemplos de como os resultados das pesquisas e os construtos teóricos são apropriados e ressignificados pelos especialistas nos diferentes sistemas de ensino na elaboração de políticas públicas. 
No que diz respeito ao inventário das pesquisas sobre formação docente, concordo com a afirmação de Nóvoa (2009, p. 14) de que dispomos de um amplo consenso quanto aos seus princípios e às medidas necessárias

[...] para assegurar a aprendizagem docente e o desenvolvimento profissional dos professores: articulação da formação inicial, indução e formação em serviço numa perspectiva de aprendizagem ao longo da vida; atenção aos primeiros anos de exercício profissional e à inserção dos jovens professores nas escolas; valorização do professor reflexivo e de uma formação de professores baseada na investigação; importância das culturas colaborativas, do trabalho em equipa, do acompanhamento, da supervisão e da avaliação dos professores etc.

No entanto, como garantir nos documentos das políticas públicas esses princípios? É certo que seus elaboradores se apropriam de muitas ideias emanadas desse movimento de investigação. Porém, como adequar tais ideias aos documentos prescritivos que chegam às escolas e aos sistemas de ensino, se ambos - documentos e sistemas - foram e estão gestados com base em princípios neoliberais de políticas educacionais?

\section{A FORMAÇÃO DOCENTE NO ÂMBITO DA NOVA CAPES}

Novas mudanças ocorreram, no cenário dos programas de formação docente, com a criação da nova CAPES, em 2007 (lei n. 11.502). Assim, a CAPES, além de coordenar o Sistema Nacional de Pós-Graduação no Brasil, passou também a ser responsável pela formação inicial e continuada de professores da educação básica.

Conforme consta no site da CAPES, a Diretoria de Formação de Professores da Educação Básica (DEB) atua em duas linhas de ação:

a. Na indução à formação inicial de professores para a Educação Básica, organizando e apoiando a oferta de cursos de licenciatura presenciais especiais, por meio do Plano Nacional de Formação de Professores da Educação Básica (PARFOR).

b. No fomento a projetos de estudos, pesquisas e inovação, desenvolvendo um conjunto articulado de programas voltados para a valorização do magistério.

Entre os programas da nova CAPES, constantes no site em julho de 2013, destacam-se: Prodocência, Programa Institucional de Bolsa de Iniciação à Docência (PIBID), Observatório da Educação (OBEDUC) e o PARFOR. ${ }^{2}$

O Prodocência é um programa de consolidação das licenciaturas que visa ao fomento à inovação e à elevação da qualidade dos cursos de formação para o magistério da educação básica, na perspectiva de valorização da carreira docente.

2 Informações extraídas de: <www.capes.gov.br>. Acesso em: 9 jul. 2013. 
O PIBID é uma iniciativa para o aperfeiçoamento e a valorização da formação de professores para a educação básica. Esse programa concede bolsas a alunos de licenciatura participantes de projetos de iniciação à docência, desenvolvidos por instituições de educação superior em parceria com escolas de educação básica da rede pública de ensino. Os projetos elaborados no âmbito desse programa visam à inserção dos graduandos no contexto das escolas públicas, durante a sua formação acadêmica, para que os estudantes desenvolvam atividades didático-pedagógicas em parceria com os professores da escola - denominados "supervisores" - e com os docentes da universidade. Todos os envolvidos no projeto recebem uma bolsa. Os números dão ideia da abrangência do programa: no início de 2013, ele contava com a participação de 195 instituições de educação superior, de todo o país, que desenvolvem 288 projetos de iniciação à docência em aproximadamente quatro mil escolas públicas de educação básica.

O OBEDUC, resultado da parceria entre a CAPES, o Instituto Nacional de Estudos e Pesquisas Educacionais Anísio Teixeira (INEP) e a Secretaria de Educação Continuada, Alfabetização, Diversidade e Inclusão (SECADI), foi instituído pelo decreto presidencial n. 5.803, de 8 de junho de 2006, com o objetivo de fomentar estudos e pesquisas em educação, que utilizem a infraestrutura disponível das instituições de educação superior e as bases de dados existentes no INEP. O programa visa, principalmente, proporcionar a articulação entre pós-graduação, licenciaturas e escolas de educação básica e estimular a produção acadêmica e a formação de recursos pós-graduados, em nível de mestrado e doutorado.

O PARFOR, na modalidade presencial, é um programa emergencial criado em 2009 e implantado em regime de colaboração entre a CAPES, os estados, os municípios, o Distrito Federal e as instituições de educação superior. Ele visa fomentar a oferta de turmas especiais em cursos de licenciatura, para os docentes e os tradutores da Língua Brasileira de Sinais (LIBRAS) já em exercício e não portadores de diploma de curso superior; segunda licenciatura, para professores licenciados, já em exercício há pelo menos três anos na rede pública de educação básica e que atuam em área distinta de sua formação inicial; e formação pedagógica, para professores ou tradutores intérpretes de LIBRAS já em exercício, mas não licenciados. Segundo consta no site da CAPES, o objetivo do programa é:

Induzir e fomentar a oferta de educação superior, gratuita e de qualidade, para professores em exercício na rede pública de educação básica, para que estes profissionais possam obter a formação exigida pela Lei de Diretrizes e Bases da Educação Nacional - LDB - e contribuam para a melhoria da qualidade da educação básica no País.

Como esses programas são ainda recentes, há um reduzido repertório de pesquisas que os avaliam. No entanto, não é objetivo, neste texto, apresentar os resultados dessas avaliações, mas apenas situar esses programas no atual contexto de projetos públicos de formação docente e apresentar, na próxima seção, os resultados de uma pesquisa vinculada a um desses programas, o OBEDUC.

Considerando que a CAPES é o órgão que avalia e regulamenta a pós-graduação no Brasil, não tenho a visão ingênua de que todos esses programas imple- 
mentados pela nova CAPES não visem ao aumento da produção acadêmica no país, uma vez que os professores pesquisadores envolvidos nesses projetos - principalmente o PIBID e o OBEDUC - publicarão os resultados das pesquisas desenvolvidas em parceria com os professores.

\section{UMA EXPERIÊNCIA NO ÂMBITO DO OBEDUC}

Como já destacado, o OBEDUC é uma iniciativa da nova CAPES que visa a explicitamente articular pós-graduação, graduação e escolas da educação básica, estimulando a produção acadêmica e a formação de mestres e doutores. A exigência do programa é de que se use o banco de dados do INEP.

Uma equipe do Programa de Pós-Graduação em Educação da Universidade São Francisco, ${ }^{3}$ sob minha coordenação, desenvolveu, no período de janeiro de 2011 a junho de 2013, o projeto "Parceria universidade-escola: múltiplos olhares para o letramento-numeramento nos anos iniciais do ensino fundamental”. Compuseram a equipe quatro professores da escola pública, quatro mestrandas e quatro docentes da universidade.

Como parte da equipe já vinha com experiências de formação docente, em parceria com escolas públicas, aproveitamos ${ }^{4}$ o contexto desse programa para desenvolver uma proposta de formação continuada com base nas necessidades dos professores. Todas as atividades do nosso projeto foram gestadas coletivamente com os professores.

Nosso objetivo era, por meio da constituição de uma comunidade investigativa, articular a formação centrada na escola com a análise do perfil de professor idealizado nos documentos prescritivos veiculados pelas políticas públicas, em especial as de avaliação, e do professor que atua na escola pública. Tomamos como eixo de problematização as práticas de letramento nos anos iniciais do ensino fundamental, em suas múltiplas vozes.

A pesquisa foi desenvolvida em quatro eixos que se articularam:

1) Parceria universidade-escola: potencialidades para a prática pedagógica e para as políticas públicas.

2) Concepção de sujeito presente nos dispositivos legais: coerência ou contraposição entre o que se espera do professor e do aluno e o que é efetivado nas avaliações externas.

3) Interpretações dos professores da escola básica das concepções de professor, de letramento e numeramento e de prática pedagógica, veiculadas nos documentos e nas provas.

4) Transformações nas práticas dos professores, decorrentes da análise e da interpretação desses documentos e provas.

3 Professoras Luzia Bueno, Márcia Aparecida Amador Mascia e Regina Célia Grando.

4 Nesta seção, o texto assume, em alguns momentos, a primeira pessoa do plural, visto que o projeto foi construído coletivamente. 
Nesse período, a equipe desenvolveu as seguintes ações: análise dos descritores e provas; análise do conjunto de prescrições que chegam até a escola; e análise das modificações ocorridas nas práticas desses professores. Foram realizadas: reuniões de estudo do grupo todo; reuniões com os envolvidos nos subprojetos que derivaram do projeto maior; parcerias entre mestrandas e professoras para planejamento, implementação e avaliação de práticas de letramento matemático em sala de aula; leituras e estudos de aprofundamentos sobre as políticas públicas e o letramento; reuniões, na escola, com o coletivo dos professores; seminários internos, com a presença de pesquisadores internacionais e nacionais.

As sistematizações da pesquisa estão incluídas no livro Entrecruzando vozes e olhares: letramentos, avaliaçôes externas e cotidiano escolar. ${ }^{5}$ Isso porque nossa crença é de que não basta dar voz e ouvir o professor: é necessário que suas reflexões e sistematizações da prática sejam compartilhadas e publicadas. Trata-se de assumir, politicamente, que o professor é pesquisador de sua prática.

A análise do material documentado durante o desenvolvimento do projeto possibilitou evidenciar as ressignificações ocorridas com temas como: políticas públicas, competências, documentos prescritivos, avaliações externas, controle do trabalho docente e práticas de letramento. Revelaram também o modo como os professores se vão constituindo profissionalmente e como buscam formas de sobrevivência nos cotidianos escolares, diante de tantas prescrições que chegam até eles. Muitas vezes, são formas de resistência ao que está posto; outras vezes, uma pseudoadesão às ingerências impostas às práticas docentes.

Entre as reflexões e as ressignificações do grupo, sem dúvida alguma, o maior destaque ficou por conta das avaliações externas, até porque elas estão influenciando diretamente as práticas dos professores em sala de aula. Nos encontros em que foram analisados os modelos da Prova Brasil e as três edições da Provinha Brasil, em especial a de matemática (a primeira edição de 2011 e as duas de 2012), os professores tomaram consciência de quanto esse tipo de avaliação se contrapõe às práticas de letramentos em sala de aula e, até mesmo, aos documentos elaborados pelos sistemas de ensino, tendo, portanto, valor apenas meritocrático e estatístico de ranqueamento das escolas, pouco contribuindo para a formação cidadã dos alunos.

Julgo oportuno trazer depoimentos dos professores participantes do projeto, ilustrando suas angústias diante de tantas ingerências às práticas escolares.

A semana passada, eu estava comentando com a Camila que a palavra "padrão" apareceu em dois dias seguidos em diferentes situações lá na escola; e eu acho que a educação está tendendo tanto para isso, como tudo na sociedade, padronizar, sistematizar, teleguiar; é incrível. Tem que atingir um padrão de qualidade, é isso e pronto! Lá na escola, aconteceu o seguinte, não é, Camila? Nós estávamos analisando, inclusive deve ser feito também com os professores e nós vamos fazer a questão dos índices de evasão, repetência e aprovação; aí nós questionamos: tem a média do município, a escola que nós estamos foi

5 Publicado pela Editora Mercado de Letras em 2013. 
analisada de acordo com a média do município; então quer dizer que o padrão é a média do município? (Professor Carlos)

Notamos a força meritocrática dos instrumentos, pois já fazem parte da nossa realidade, o que nos resta é refletir sobre como trabalhar com os dados a favor de uma aprendizagem melhor aos nossos alunos, lembrando sempre da realidade na qual nos encontramos e do sistema de ensino do qual fazemos parte. [...] Diante do cenário atual, enquanto professores, vivemos sempre em função de políticas públicas que ditam como devemos desenvolver a capacidade de saber avaliar e, muitas vezes, não é definido de forma clara qual o papel do professor. Dessa forma, é preciso identificar as reais contradições entre o que é proposto pelas políticas públicas, como as avaliações externas, e os descritores apresentados por tais instrumentos, bem como as relações de ensino e de aprendizagem e as condições das escolas. (Professora Daniela)

O maior problema desse tipo de avaliação, como já foi discutido durante várias vezes nos encontros, é que se "mede" o ensino apenas em uma prova, na maioria das vezes mal elaborada, que será responsável pelas estatísticas de qualidade. E, como todas as instituições são obrigadas a participar, temos que entrar no jogo das políticas públicas para tentar modificá-lo, se possível; ou seja, de alguma forma, tentar melhorar os níveis dos alunos nessas avaliações e continuar fazendo um bom trabalho dentro das instituições escolares para que todos avancem no processo de ensino aprendizagem. (Professora Eliana)

Os pontos negativos das avaliações (no caso de nossa rede são: SARESP, Provinha Brasil, Prova Brasil e, agora, em 2011, Prova Municipal) ficam por conta de não ser levada em consideração a realidade em que a escola está inserida, somente a nota, e, no caso da Prova Brasil, também o índice de evasão e repetência são considerados no resultado final da escola; não se analisa o tipo de clientela que a escola atende, que tipo de profissionais trabalham nessa escola, nem em qual comunidade a escola está inserida. Acaba existindo uma comparação injusta entre as escolas, pois não se podem comparar escolas com realidades diferentes e exigir que os desempenhos sejam os mesmos, pois pode haver uma escola que, se comparada à outra, esteja com baixo desempenho; porém, se comparada a si mesma, ela avançou muito. (Professora Camila)

Ao selecionar esses depoimentos, entre tantos outros documentados na pesquisa, quis evidenciar a angústia dos professores diante das avaliações externas e das políticas de padronização e mensuração do trabalho nas escolas. Em todas as reuniões da equipe, abríamos espaço para ouvir os professores e suas angústias sobre a quantidade de prescrições que chegam até a escola e os impedem de desenvolver um trabalho que acreditam que seja a favor do aluno e de sua aprendizagem. Bom exemplo dessa constatação ocorreu no município de Itatiba/SP, onde a pesquisa foi desenvolvida: no mês de novembro, a rede municipal realiza três tipos de avaliação: Prova Brasil e/ou Provinha Brasil, Sistema de Avaliação de Rendimento Escolar do 
Estado de São Paulo (SARESP) e a avaliação do município. E todas elas centram-se em língua portuguesa e matemática. Por que somente essas disciplinas? Concordo com Freitas (2011, p. 80):

Os reformadores empresariais argumentam que Português e Matemática são o básico para se formar para a cidadania. [...] O problema em limitar-se ao básico é que o básico, por definição, exclui aquilo que se considera que não é básico. $\mathrm{E}$ isso é uma decisão ideologicamente orientada. As artes, o corpo, os sentimentos, a afetividade, a criatividade devem ser desenvolvidas simultaneamente, e não após o básico. As crianças das camadas populares só têm a escola para desenvolver tais habilidades. Não passam duas vezes pela escola: primeiro para aprender o básico e depois para expandir o básico. É um engodo, portanto, falar que o básico vem primeiro. Portanto, o que essa decisão esconde é que ela aceita, na verdade, que a escola forma cidadãos de segunda categoria (para quem o básico é suficiente) e cidadãos de primeira categoria (para quem o ciclo educacional se expande para além do básico).

O que é possível destacar das falas desses professores? As avaliações externas buscam padronizar escolas e contextos muito diferentes, conforme destacou a professora Camila. Além disso, usa-se como média de referência o próprio município (conforme fala do professor Carlos). Ora, se a média do município for baixa, padroniza-se "por baixo"? Essas são questões que raramente são discutidas e refletidas nos debates sobre avaliação.

Outro ponto a ser destacado refere-se aos descompassos entre o que consta nos próprios documentos e o que se cobra nas avaliações. Os documentos que acompanham as avaliações e são considerados fontes de orientação para os professores apontam para algumas práticas que não são contempladas nas avaliações. No caso específico da matemática, Galvão e Nacarato (2013) compararam o conteúdo desses documentos e as provas, identificando os descompassos existentes. Se os professores não tiverem a postura crítica das professoras Daniela e Eliana e se limitarem a trabalhar com o conteúdo presente nessas etapas, estarão privando seus alunos de um conhecimento matemático mais significativo e crítico.

Considero que nosso projeto foi de resistência ou de pseudoadesão aos princípios do OBEDUC. Isso porque aderimos a ele pela possibilidade de os professores terem a bolsa para poder dedicar-se ao projeto e realizar pesquisas. Se quisermos que os professores sejam pesquisadores, temos de dar a eles condições para a realização de pesquisas; assim, com a bolsa, os participantes do OBEDUC não precisam dobrar jornada de trabalho, o que facilita a participação no projeto. Mas o programa exigia o uso de dados do INEP. Nós utilizamos os dados das avaliações externas; estudamos todos os documentos que acompanham a Prova Brasil, a Provinha Brasil e a prova do Exame Nacional de Desempenho dos Estudantes (ENADE)/Pedagogia; avaliamos os conteúdos dessas provas - no caso da Prova Brasil, o INEP disponibiliza apenas um modelo de prova; acompanhamos a aplicação de três edições da Provinha Brasil, aplicada aos alunos do segundo ano; e avaliamos os resultados e as análises que as professoras responsáveis por essas turmas realizaram nesses dois anos. 
Todo esse movimento aconteceu com a leitura e a discussão de textos que contextualizam esse cenário das políticas públicas, desde o documento do Banco Mundial, ${ }^{6}$ de 1995, até textos mais recentes sobre as reformas educacionais. A compreensão desse contexto pelos professores possibilitou que eles se tornassem mais críticos e, principalmente, vislumbrassem as potencialidades de um trabalho em parceria, tal como destacado pela professora Daniela em sua narrativa publicada no livro do projeto:

Uma das primeiras aprendizagens foi a de desmitificar o que seria uma parceria entre universidade e escola. No início, acreditava que seria mais uma dessas reuniões onde professores, estudiosos e pesquisadores da área da Educação estariam ali para transmitir anos de procedimentos técnicos de instrumentos didáticos. No entanto, fui aprendendo que minha construção da identidade de professora precisava receber uma valorização e que a reconstrução dos meus conhecimentos só estaria sendo completada a partir do momento em que o Projeto proporcionasse a multiplicidade dos olhares, trocas entre os participantes, daquilo que cada um tinha sobre o que é ensinar e trabalhar em parceria. (Souza, 2013, p. 47)

O depoimento da professora Daniela sinaliza quanto o professor está descrente dos projetos que chegam à escola. A construção de parcerias é um processo longo, demanda respeito pelo trabalho do outro: os professores acadêmicos precisam colocar-se à escuta dos professores da escola básica e trabalhar na perspectiva de que o que estes têm a dizer tem importância e precisa ser o ponto de partida para um trabalho coletivo; os professores da escola básica, por sua vez, à medida que sentem confiança nos formadores, aderem à proposta de trabalho coletivo. Assim, a parceria potencializa aprendizagens recíprocas.

\section{A PARCERIA UNIVERSIDADE-ESCOLA: UTOPIA OU POSSIBILIDADE DE FORMAÇÃO CONTINUADA?}

Entendo que a parceria universidade-escola precisa ser uma construção coletiva, pautada no respeito e na abertura ao diálogo. Não há manual de orientação para fazê-la acontecer; ela é construída no processo. Dessa forma, há que ficar atento para que essa concepção de formação não comece a ser prescrita pelos documentos oficiais.

Desde o início dos anos 2000, trabalhos como os de Cochran-Smith e Lytle (1999) e de Pereira e Zeichner (2002) têm orientado minhas práticas de formação docente. O diálogo com essa literatura e a participação em espaços de trabalho colaborativo têm possibilitado a constituição de grupos de trabalho com professores de diferentes níveis de ensino, os quais se assumem como comunidades de aprendizagem

6 Priorities and strategies for education: a World Bank sector review (Prioridades e estratégias para a educação: estudo setorial do Banco Mundial) (Tommasi; Warde; Haddad, 1996). 
(Cochran-Smith; Lytle, 1999; Hargreaves, 2004), superando a dissociação entre pesquisas dos professores e pesquisas acadêmicas (Zeichner, 1998).

Esses grupos/comunidades necessitam estabelecer agendas de trabalho pautadas em estudos, problematização e análise das práticas, análise crítica dos documentos que chegam às escolas, sempre levando em consideração o contexto no qual cada escola está inserida e o perfil de seus alunos - assim é que ocorre a formação "sentada na escola" (Canário, 2000).

O Programa OBEDUC, ao possibilitar o acesso aos dados das escolas no INEP e disponibilizar alguns documentos, tem favorecido que boas parcerias sejam estabelecidas, gerando projetos de formação continuada na própria escola.

A pesquisa realizada nesse contexto evidenciou quanto os professores se tornaram consumidores críticos dos documentos que chegam à escola e acabam norteando suas práticas. Como aqui revelaram os professores participantes do projeto, eles seguem a regra do jogo, mas criam táticas de resistência, em favor de uma educação de qualidade para seus alunos.

Não posso deixar de destacar que formações como as aqui relatadas são realizadas em contextos reduzidos. $\mathrm{O}$ questionamento que fica: Como atingir o grande contingente de professores do país? Mesmo no caso da pesquisa relatada, ela não foi realizada com todo o coletivo da escola, embora a equipe tenha realizado várias ações na unidade, conforme as necessidades que nos foram levadas pelos participantes do projeto.

Novas indagações poderão ser feitas. Para algumas, já existem pesquisas; para outras, faz-se necessário ampliar os objetos de investigação, buscando avaliar de modo mais abrangente os alcances desses programas públicos de formação docente. No entanto, não se pode deixar de levar em consideração que nenhuma reforma ou proposta educacional terá efeito positivo se não forem modificadas as condições de trabalho dos professores da escola básica, principalmente: plano de carreira, redução da jornada de trabalho em sala de aula e melhores salários.

Da mesma forma como iniciei o texto, finalizo concordando com Nóvoa (2013, p. 206):

Nada será conseguido se não se alterarem as condições existentes nas escolas e as políticas públicas em relação aos professores. É inútil apelar à reflexão se não houver uma organização das escolas que a facilite. É inútil reivindicar uma formação mútua, interpares, colaborativa, se a definição das carreiras docentes não for coerente com este propósito. É inútil propor uma qualificação baseada na investigação e parcerias entre escolas e instituições universitárias, se os normativos legais persistirem em dificultar esta aproximação.

Nas condições atuais, com a intensificação e a regulação do trabalho docente, muitas vezes a sobrevivência na profissão se dá pela criação de práticas de resistência ou de pseusoadesão às políticas públicas. 


\section{REFERÊNCIAS}

Brasil. Conselho Nacional de Educação. Conselho Pleno. Resolução n. 1, de 18 de fevereiro de 2002. Institui Diretrizes Curriculares Nacionais para a Formação de Professores da Educação Básica, em nível superior, curso de licenciatura, de graduação plena. Diário Oficial da União, Brasília, 9 abr. 2002. Seção 1, p. 31

Canário, R. A prática profissional na formação de professores. In: CAmpos, B. P. (Org.). Formação profissional de professores no ensino superior. Aveiro: INAFOP, 2000.

Cochran-Smith, M.; Lytle, S. L. Relationships of knowledge and practice: teacher learning in communities. Review of Research in Education, United Kingdom: Sage; AERA, n. 24, p. 249-305, 1999.

Freitas, H. C. L. A (nova) política de formação de professores: a prioridade postergada. Educação E Sociedade, Campinas: CEDES, v. 28, n. 100, p. 1.203-1.230, out. 2007.

FreitAs, L. C. Os reformadores empresariais da educação: a consolidação do neotecnicismo no Brasil. In: Fontoura, H. A. Politicas públicas, movimentos sociais: desafios à pós-graduação em educação em suas múltiplas dimensões. Rio de Janeiro: ANPEd, 2011. p. 72-90 (E-book).

Gatti, B. A.; Barreto, E. S. S. (Coords.). Professores do Brasil: impasses e desafios. Brasília: UNESCO, 2009.

Galvão, E. S.; Nacarato, A.M. O letramento matemático e a resolução de problemas na Provinha Brasil. Revista Eletrônica de Educação, São Carlos: UFSCar, v. 7, p. 81-96, 2013.

Hargreaves, A. O ensino na sociedade do conhecimento: educação na era da insegurança. Porto Alegre: Artmed, 2004.

Nacarato, A. M.; Grando, R. C.; Toricelli, L.; Tomazetto, M. Professores e futuros professores compartilhando aprendizagens: dimensões colaborativas em processo de formação. In: ___ PAIva, M. A. V. A formação do professor que ensina matemática: perspectivas e pesquisas. Belo Horizonte: Autêntica, 2008. p. 197-212.

NóvoA, A. Professores: imagens do futuro presente. Lisboa: Educa, 2009.

Nada substitui um bom professor: propostas para uma revolução no campo da formação de professores. In: Gatti, B. A.; Silva Júnior, C. A.; Nicoletti, M. G.; Pagotto, M. D. S. (Orgs.). Por uma politica de formação de professores. São Paulo: Editora da UNESP, 2013. p. 199-210.

Passos, C. L. B.; Nacarato, A. M.; Fiorentini, D.; Miskulin, R. G. S.; Grando, R. C. et al. Desenvolvimento profissional do professor que ensina matemática: uma meta-análise de estudos brasileiros. Quadrante - Revista de Investigação em Educação Matemática, Lisboa: APM, v. XV, n. 1-2, p. 193-219, 2006.

Pereira,J. E. D. A pesquisa dos educadores como estratégia para construção de modelos críticos de formação docente. In:_—_ ZeIchNer, K. M. A pesquisa na formação e no trabalho docente. Belo Horizonte: Autêntica, 2002. p. 11-42.

Autêntica, 2002. 
Pimenta, S. G. Professor reflexivo: construindo uma crítica. In: Pimenta, S. G.; Ghedin, E. (Orgs.). Professor reflexivo no Brasil: gênese e crítica de um conceito. São Paulo: Cortez, 2002. p. 17-52.

São Paulo (Governo do Estado). Secretaria da Educação. Coordenadoria de Gestão da Educação Básica. Projeto Educação Matemática nos Anos Iniciais do Ensino FundamentalEMAI. São Paulo: CGEB, s.d. Disponível em: <http://docslide.com.br/documents/ emai-texto-apoio-expectativas.html>. Acesso em: 16 maio 2016.

SouzA, D. A. A flor de Samuel: um olhar docente sobre uma prática pedagógica ressignificadas na e pela convivência da parceria universidade-escola. In: NacArato, A. M.; Souza, D. A.; Betereli, K. C. (Orgs.). Entrecruzando vozes e olhares: letramentos, avaliações externas e cotidiano escolar. Campinas: Mercado de Letras, 2013. p. 45-64. Tommasi, L.; Warde, M. J.; Haddad, S. O Banco Mundial e as politicas educacionais. São Paulo: Cortez Editora, 1996.

Zeichner, K.M. Para além da divisão entre professor pesquisador e professor acadêmico. In: Geraldi, C.; Fiorentini, D.; Pereira, E. M. A. (Orgs.). Cartografias do trabalho docente: professor(a) pesquisador(a). Campinas: Mercado de Letras, 1998. p. 207-236.

\section{SOBRE A AUTORA}

Adair Mendes Nacarato é doutora em educação pela Universidade Estadual de Campinas (UNICAMP).É professora da Universidade São Francisco (USF).

E-mail: adamn@terra.com.br 